\title{
Study on the Structure and Properties of Novel Bio-based Polyamide56 Fiber Compared with Normal Polyamide Fibers
}

\author{
Xinmin $\mathrm{Hao}^{1,}$, , Yafei Guo ${ }^{2}$, Yueling $\mathrm{Li}^{1,2}$, Yuan $\mathrm{Yang}^{3}$, Yuhong Shen $^{1}, \mathrm{Xi}$ \\ $\mathrm{HaO}^{3}$ and Jianming Wang ${ }^{2, \mathrm{~b}}$ \\ ${ }^{1}$ The Quartermaster Research Institute of the General Logistics Department of the PLA, Beijing, \\ 100082, China \\ ${ }^{2}$ Beijing Institution of Fashion Technology, Beijing, 100019, China \\ ${ }^{3}$ Youxian Technology (Dandong) Co., Ltd.,Liaoning, 118000, China \\ aemail: xminhao@126.com, bemail: wangjm1502@163.com
}

Keywords: Bio-based Fiber; Polyamide56; Polyamide6; Polyamide6; Structure; Property

\begin{abstract}
The new kind of bio-based polyamide56 fiber has been synthesized by adipic acid and 1,5-pentanediamine, which was prepared by fermenting a variety of starch. The spin ability, physical and thermal properties of bio-based PA56, PA 6 and PA 66 were evaluated through systematic investigation and measurement. Bio-based polyamide56 resin has been proved to have good spin ability. PA56 have more concentrated distribution of molecular weight than other nylons, which indicated more stable viscosity beneficial for spinning and higher fiber strength. The infrared spectrum showed characteristic amide and methylene absorption peaks of PA56 but different vibration intensities with conventional nylon, which demonstrates different molecular structure. Differential scanning calorimetry combined with thermal gravimetric revealed good heat resistance (the thermal decomposition temperature is $403.7^{\circ} \mathrm{C}$ ) and high melting-point $\left(254.1{ }^{\circ} \mathrm{C}\right)$ of polyamide56. X-ray diffraction of these fibers were proposed and showed that slightly higher crystallinity of polyamide56 so as to have more regular arrangement of molecular.
\end{abstract}

\section{Introduction}

Polyamide, referred to PA and commonly called nylon, is one of the most important modern industrial materials, which has widespread in many areas of military equipment, automotive and textiles. The most industrial and widely used polyamidefibers currently are polyamide6 and polyamide66, whose raw materials more dependent on petrochemical products. Studies suggest that polyamide56 synthesized by pentamethylene diamine have more perfect performance. But, it is much expensive to produce odd polyamidemonomers by petrochemical methods. Discovering or producing renewable resources to replace petroleum based raw materials is a major concern in terms of both economic and environmental viewpoints [1-3].

There have been decades to displace petrochemical based diamine by fermentation and enzyme methods in lots of big international enterprise such as BASF, Degussa in Europe and Toray, Ajinomoto in Japan, trying to obtain industrialized technology through decarboxylation of lysine which failed to access to markets for the too high cost. More recently, biological pentamethylene diamine technology has made a major breakthrough [4][5]. Pentamethylene diamine were prepared successfully by fermentation from starch in our study. Enzymatic efficiency of microbial strains genetically engineered has been improved greatly, which reduced production costs, so it made quality and price of biological diamine could meet the quality requirements of polyamidepolymerization [6-8]. Joined with Liaoning chemical industry group and other relevant units, logistics department quartermaster equipment institute have been made a large number of studies on polymerization, modification, spinning and other aspects of nylon56, and produced polyamide56 staple fiber and filament yarn successfully for the first time and made the appropriate clothing, which initially solved polymerization and spinning process problems of polyamide56 fiber. At the same time we made a breakthrough in the blended yarn and textile processing of 
polyamidefiber, and laid the foundation for the production and development of bio-based polyamidefiber. Bio-based polyamide56 fiber is expected to be advanced materials used in clothing and industrial textiles [9-12]. This paper discusses on several basic performances closely related to applications of textile and apparel.

\section{Material and Methods}

Polyamide56 resin, synthesized by pentamethylene diamine and adipic acid, both of which were prepared by fermenting a variety of starch and cellulose in straw, was provided by the quartermaster research institute of the general logistics department. 166dtex/72f PA56 filament was provided by the quartermaster research institute of the general logistics department; 154dtex/36f PA6 filament and 233dtex/ PA6 filament were produced by Guangdong Xinhui meida polyamideCo., Ltd.; 110dtex/34f PA66 filament was provided by Liaoning Yinzhu textile Group Co., Ltd. All the materials are used as obtained.

PA56 resin were spined by single screw spinning machine with a screw diameter of 30mm, spinneret aperture of $0.3 \mathrm{~mm}$ and $72 \mathrm{f}$. One-trip technology of spinning and drawing was used when spinning with a spinning speed of $2000 \mathrm{~m} / \mathrm{min}$.

Molecular weight of polyamide fibers were investigated using GPC-2000 gel permeation chromatography (gel column was Waters Styragel @ HT DMF $7.8 \times 300 \mathrm{~mm}$ Column). Took PA6, PA66 and PA56 respectively about $5 \mathrm{mg}$ and dissolved in m-cresol of 7-8mL until completely dissolved. The filtrate for use was poured into the sample tube after filtration by syringe.

The total reflection spectra scanning of polyamidefibers were performed on FTIR-BRUKER Tensor27 respectively at $20 \mathrm{C}$ with scanning range of $400 \sim 4000 \mathrm{~cm}^{-1}$.

To determine the thermal characteristics, DSC were performed on EXSTAR DSC 6200 differential scanning calorimeter (manufacturer SII) under nitrogen flow at $20 \mathrm{~mL} / \mathrm{min}$. The samples were heated from room temperature up to 300 Cat $20 \mathrm{C} / \mathrm{min}$. Then, samples were (placed in the crucible on the ice) were quickly cooled to $0 \mathrm{C}$ to eliminate the thermal history. Then, samples were cooled to $-50 \mathrm{C}$ at $20 \mathrm{C} / \mathrm{min}$ and heated again to $300 \mathrm{Cat} 20 \mathrm{C} / \mathrm{min}$. The glass transition $\mathrm{Tg}$ and the melting temperature Tm were determined respectively from the inflexion point and the maximum of melting temperature peak. These values were determined on the second heating scan.

TG-DTA combined analyzer of 6300-type was also used to determine the thermal characteristic. The samples (a certain amount in the ceramic crucible) were designed to heat from 30 Cto 550 Cat $10 \mathrm{C} / \mathrm{min}$. The characteristic degradation temperatures are the temperatures at maximum of the derivative thermo gram curve.

The XRD patterns were obtained with experimental set-up of $1 \mathrm{~mm}$ length. In all cases, a linear monochromatic $\mathrm{Cu}-\mathrm{Ka}_{1}$ beam $(\lambda=1.5406 \AA)$ was obtained using a sealed-tube generator (200W) equipped with a bent monochromator. A Debye-Scherer like geometry was used. The crude film was filled in Lindeman capillaries of $1 \mathrm{~mm}$ diameter and $10 \mathrm{~mm}$ thickness. The diffraction pattern was recorded on an image plate. Periodicities up to $80 \AA$ can be measured, and the sample temperature controlled within 0.1Cfrom 20 to $200 \mathrm{C}$.

\section{Results and Discussions}

The viscosity of PA56 resin is 145.85 , and terminal amino group is 0.0221 . The continuous smooth spinning with no bristles under the experimental spinning conditions for 72 hours suggested that PA56 is spinable and spinning smoothly under the experimental spinning conditions .Performance test results of PA56 filament fibers are as shown in Table 1.It is worth mentioning that elongation at break and boiling water shrinkage is too large and strength needs to be improved[13].Therefore, as a new polymer material, related polymer synthesis, preparation and other basic research and technology of PA56 are still in infancy and starve for further study. 
Table 1 Performance of PA56fiber

\begin{tabular}{|c|c|c|c|}
\hline & fracture strength, & elongation at & boiling water \\
\hline denier, & cN/dtex & break, \% & shrinkage, \% \\
\hline 166 & 3.9 & 42 & 17 \\
\hline
\end{tabular}

Molecular weight and its distribution have a greater impact on the processing performance, mechanical properties, crystallization properties and heat resistance of fiber. Thus, it is very important to determine the molecular weight and its distribution. The molecular weight of the samples measured are as shown in Table 2. Mp is the peak molecular weight. It is obvious that the distribution of molecular weight of polyamide56 is relatively narrow than polyamide 6 and polyamide66, which indicates high degree of crystallinity and more stable viscosity beneficial for spinning and higher fiber strength[14][15].

Table 2 The molecular weight of different polyamidefiber samples measured

\begin{tabular}{ccccccc}
\hline sample & $\mathrm{M}_{\mathrm{n}}$ & $\mathrm{M}_{\mathrm{w}}$ & $\mathrm{M}_{\mathrm{P}}$ & $\mathrm{M}_{\mathrm{z}}$ & $\mathrm{M}_{\mathrm{z}^{+}}$ & distribution of \\
\hline PA6 & 733 & 112 & 102 & 161 & 210 & 1.531845 \\
PA66 & 654 & 103 & 889 & 152 & 205 & 1.575487 \\
PA56 & 636 & 932 & 794 & 131 & 172 & 1.465005 \\
\hline
\end{tabular}

IR curves of the measured three polyamidefibers are as shown in Figure 1. Comparative analysis of the position and the peak intensity of each peak shape finds that the peak shape and position of PA56, PA66, and PA6 are different. Table 3 shows part of the attributable spectrum, such as the peak position and vibration intensity of N-H Fermi resonance and stretching resonance in amide II are all different [16][17]. These differences can prove PA56 a new material having different structure from PA6 and PA66.

Table 3 parts of band assignment of different polyamidefibers

\begin{tabular}{|c|c|c|c|c|c|c|}
\hline \multicolumn{2}{|c|}{ PA66 } & \multicolumn{2}{|l|}{ PA6 } & \multicolumn{2}{|c|}{ PA56 } & \multirow{2}{*}{$\begin{array}{c}\text { band } \\
\text { assignment }\end{array}$} \\
\hline $\begin{array}{l}\text { peak position } \\
(\mathrm{cm}-1)\end{array}$ & $\begin{array}{l}\text { peak } \\
\text { intensity }\end{array}$ & $\begin{array}{l}\text { peak position } \\
(\mathrm{cm}-1)\end{array}$ & $\begin{array}{l}\text { peak } \\
\text { intensity }\end{array}$ & $\begin{array}{l}\text { peak position } \\
\text { (cm-1) }\end{array}$ & $\begin{array}{l}\text { peak } \\
\text { intensity }\end{array}$ & \\
\hline 3290 & 70.7 & 3290 & 85.6 & 3310 & 82.1 & N-H \\
\hline 3070 & 90.6 & 3050 & 95.2 & 3080 & 94.3 & $\begin{array}{l}\mathrm{N}-\mathrm{H} \text { Fermi } \\
\text { resonance and }\end{array}$ \\
\hline 2930 & 75.6 & 2930 & 89.0 & 2940 & 86.7 & $-\mathrm{CH}_{2}-$ \\
\hline
\end{tabular}

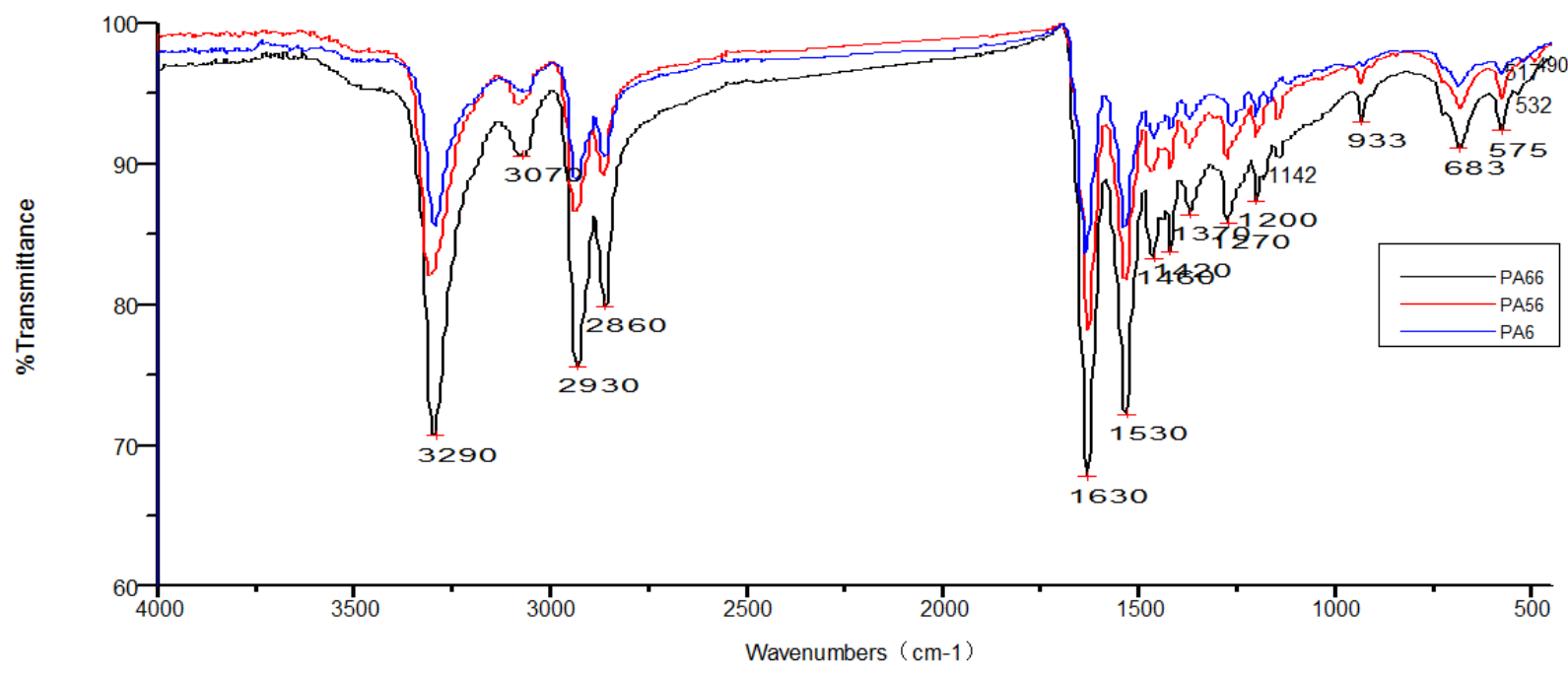

Fig. 1. IR spectra of different polyamidefibers 
The thermal behavior of the three polyamidefibers was investigated by DSC. Figure 2 shows the thermal properties of the different fibers. Glass transition temperature $\left(\mathrm{T}_{\mathrm{g}}\right)$, heats of crystallization $\left(\triangle \mathrm{H}_{\mathrm{c}}\right)$, crystallization temperature $\left(\mathrm{T}_{\mathrm{c}}\right)$, melting temperatures $\left(\mathrm{T}_{\mathrm{m}}\right)$, and melting heats $\left(\triangle \mathrm{H}_{\mathrm{m}}\right)$ can be determined and calculated from the DSC thermo grams[18]. The melting temperature of PA6 filaments, PA66 filaments, PA56 filaments obtained from Fig. 2are 224.2C, 249.3C, 254.1C. The thermal decomposition temperature of PA6 filaments, PA66 filaments, PA56 filaments are 419.8C, 405.0C, 403.7C as shown in Figure 3. There may be slightly differences in results due to different testing methods [19]. Amides groups of PA56 are staggered along the direction of polymer long chain, repeatedly arranged as"5-4-5-4" in the spatial position. So each functional group is capable to form hydrogen bonds [20] in the absence of deformation of the molecule that explain a higher melting point and thermal decomposition temperature. It is mentioning that bio-based polyamide56 have better heat resistance [21] and base of applications at higher temperature than polyamide6.

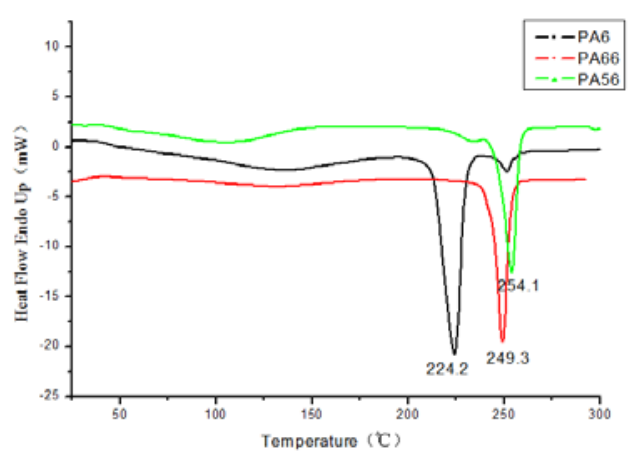

Fig. 2. DSC curves of different polyamidefibers

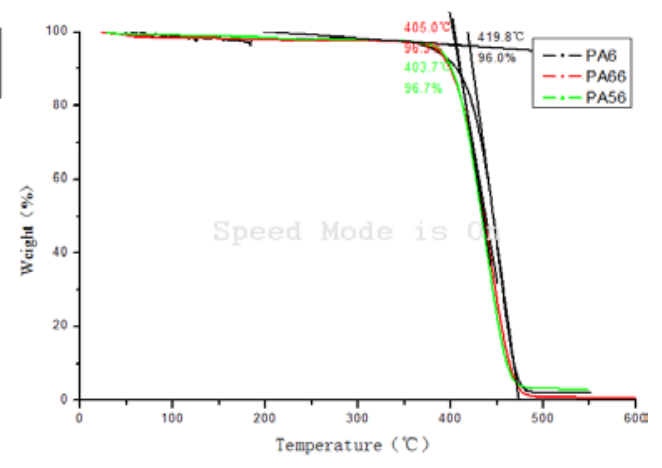

Fig. 3. TG curves of different polyamidefibers

Limited results reported show that the polyamide56 has two polymorphs, fake hexagonal and monoclinic phase at elevated temperatures occur during the Brill transition [22]. Several XRDpolyamidefiber shown in Figure 4 were tested. Apparently from the figure, PA56 has different polymorphs from PA6 and PA66.The result of profile fitting suggests the degree of crystallinity of PA56is slightly higher than PA6 and PA66, which means more regular arrangement of PA56 molecules and explains the higher melting point. Conventional polyamide generally induced a transition towards a pseudo hexagonal unit cell, which transition can be easily observed by X -ray diffraction pattern since the two strong equatorial reflections characteristic of the sheet structure gradually merge by increasing temperature into a single reflection. This temperature is called Brill transition temperature. There have been a lot of studies about Brill transition reported, but lack of a widely accepted explanation for varieties of assumptions. The studies by Laura et al. figured that Brill transition of polyamide56is irreversible caused by increased mobility of polyethylene and bring no damage on hydrogen in the shift process.

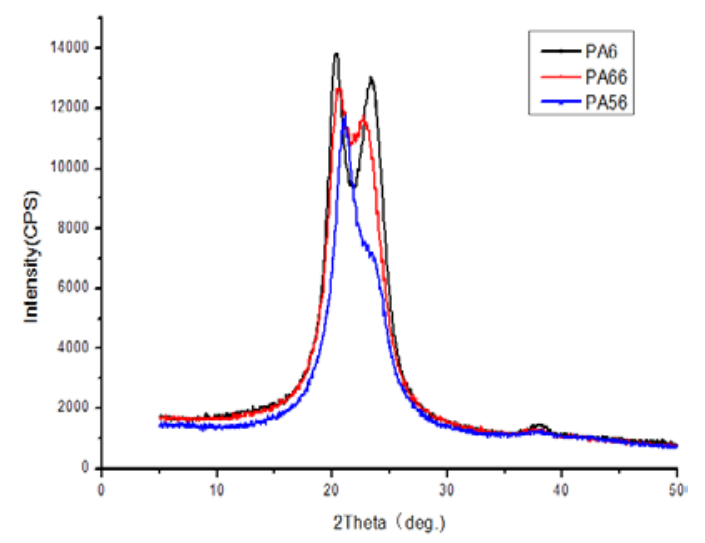

Fig. 4. XRD curves of different polyamidefibers 


\section{Conclusion}

This study showed that the bio-based PA56 can be spined smoothly under the experimental spinning conditions. The molecular weight comparative study indicated a narrow distribution of molecular weight of polyamide56, which is in good agreement with the result of XRD test that indicated the degree of crystallinity of PA56 is slightly higher than PA6 and PA66. The higher the degree of crystallinity, the higher fiber strength and more stable viscosity which is beneficial for spinning. The structure of PA6, PA66 and bio-based PA56 were investigated by IR curves analysis. Experimentalresultsshowthat the melting point of bio-based PA56 is $254.1^{\circ} \mathrm{C}$ which is higher than that of PA6 and PA66, and thermal decomposition temperature is $403.7^{\circ} \mathrm{C}$ which is slightly lower than that of PA6 and PA66.The results indicate that bio-based PA56 fiber has good heat resistanceproperty and could be appliedinhightemperatureenvironment. All in all, research of novel bio-based polyamide56 reported is much limited. The bio-based polyamide56 is widely applied in many fields because of its excellentproperties.

\section{Acknowledgement}

We thank for the financial supports of the research from The Beijing Training Project for the Leading Talents in S \& T (Project No. LJ201424).

\section{References}

[1] Jian Cao, Zhenhua Ding, Xinyuan Shen. Status and Development Trends of the Novel Bio-fiber[J]. Fiber and Its Wide Watch, 2012, 1: 82-86.

[2] Dong Ji, Zheng Fang, Pingkai Ouyang, et al. Progress in bio-bassed polyamides[J]. Chinese Journal of Bioprocess Engineering, 2013, 11(2): 73-80.

[3] Elodie Hablot, Bertrand Donnio, Michel Bouquey, et al. Dimer acid-based thermoplastic bio-polyamides: Reaction kinetics, properties and structure. Polymer, 2010, 51(25): 5895-902.

[4] Baiquan Chen, Zhijie Huang, Xin Zhang. A biodegradable nylon/starch composite and preparation method: China, CN201310112187.X[P]: 2013-07-31.

[5] Mingjuan Qian, Wei Deng, Chi Liu. A polyamidefiber: China, CN 201310060413.4[P]: 2013-02-26.

[6] Yi Zheng, Bin Qin, Chi Liu. A semi-aromatic polyamides and preparation method: China, CN 201310329614.X[P]: 2013-11-13.

[7] Zhen Pang, Ning Li, Chi Liu. Plasmid recombinant expressed stably in Hafnia alvei and application: China, CN 201210177392.X[P]: 2012-05-31.

[8] Zhiyong Jiang, Yujing Tang, Jens Rieger, Hans-Friedrich Enderle, Dieter Lilge, et al. Two Lamellar to Fibrillar Transitions in the Tensile Deformation of High-Density Polyethylene[J]. Macromolecules. 2010, 43(10):4727-32.

[9] Zhiyong Jiang, Yujing Tang, Jens Rieger, Hans-Friedrich Enderle, Dieter Lilge, Roth Stephan V., et al. Structural evolution of tensile deformed high-density polyethylene at elevated temperatures: Scanning synchrotron small- and wide-angle X-ray scattering studies[J]. Polymer. 2009, 50(16):4101-11.

[10] Navarro Eloisa, Franco Lorenzo, Subirana J.A., Puiggali Jordi. Polyamide65 has a unique structure with two directions of hydrogen bonds. Macromolecules. 1995, 28(26):8742-8750.

[11] Jianqi Zhang, Shanshan Hu, Rieger Jens, Roth Stephan V., Gehrke Rainer, Yongfeng Men. In Situ Observation of Tensile Deformation Processes of Soft Colloidal Crystalline Latex Fibers[J]. Macromolecules. 2009, 42(13):4795-4800. 
[12] Laura Morales-Gámez, David Soto, Lourdes Franco, et al. Brill transition and melt crystallization of polyamide56: An odd-even polyamide with two hydrogen-bonding directions[J]. Polymer,2010, 51(24):5788-5798.

[13] Laura Morales-Gámez, David Soto, Lourdes Franco, et al. Brill transition and melt crystallization of polyamide56: An odd-even polyamide with two hydrogen-bonding directions[J]. Polymer,2010, 51(24):5788-5798.

[14] Siie Wang, Yongan Lin. Acid dyeing of polyamideelastic knits with low liquor ratio[J]. Printing and Dyeing, 2013, 3:22-26

[15] Xushan Wang, Guotao Yang, Aijun Wang, et al.The research and development of dyeing and finishing technology foracetate/polyamideintertexture[J]. Textile Dyeing and Finishing Journal, 2013, 35(5):21-22.

[16] Shiyue Liu, Chenguo Li, Jingbo Zhao, et al. Synthesis and characterization of polyesteramides having short Nylon-6 segments in the main chains through polycondensation and chain extension[J]. Polymer, 2011, 52: 6046-55.

[17] Puiggalí Jordi, Lourdes Franco, Alemán Carmen, et al. Crystal Structures of Polyamide5,6. A Model with Two Hydrogen Bond Directions for Nylons Derived from Odd Diaminuteses[J]. Macromolecules,1998,31 (24):8540-8.

[18] Chongyang Liu, Guozhang Wu, Kun Zhang, Jiandi Jiang. Thermal expansion behavior of aliphatic polyam mes[J]. Acta Polymerica Sinica, 2013, 2: 255-262.

[19] Marco Lai, J. Botsis, Joel Cugnoni, et al. An experimental-numerical study of moisture absorption in an epoxy. Composites:Part A, 2012, 43: 1053-1060.

[20]In-Chul Yeh, B.Christopher Rinderspacher, Jan W. Andzelm., Lashonda T. Cureton, John La Scala. Computational study of thermal and mechanical properties of nylons and bio-based furan polyamides. Polymer, 2014, 55: 166-74.

[21] Koichiro Tachibana, Yuichi Urano, Keiji Numata. Biodegradability of polyamide4 film in a marine environment. Polymer Degradation and Stability, 2013, 98: 1847-51.

[22]Jie Zhang, Panpan Tian, Xinfa LI, Jinzhou Chen, et al. Study on Thermal Properties of PA6T/1010 Copolymer[J]. Plastics Science and Technology, 2013, 41(2): 62-66. 